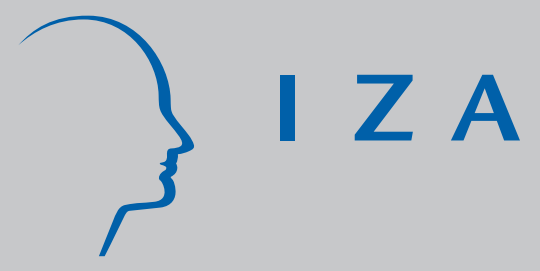

IZA DP No. 607

How Do Firms Redline Workers?

Yves Zenou

October 2002 


\title{
How Do Firms Redline Workers?
}

\author{
Yves Zenou \\ University of Southampton, GAINS, \\ CEPR and IZA Bonn
}

\author{
Discussion Paper No. 607 \\ October 2002
}

\author{
IZA \\ P.O. Box 7240 \\ D-53072 Bonn \\ Germany \\ Tel.: +49-228-3894-0 \\ Fax: +49-228-3894-210 \\ Email: iza@iza.org
}

This Discussion Paper is issued within the framework of IZA's research area The Future of Labor. Any opinions expressed here are those of the author(s) and not those of the institute. Research disseminated by IZA may include views on policy, but the institute itself takes no institutional policy positions.

The Institute for the Study of Labor (IZA) in Bonn is a local and virtual international research center and a place of communication between science, politics and business. IZA is an independent, nonprofit limited liability company (Gesellschaft mit beschränkter Haftung) supported by the Deutsche Post AG. The center is associated with the University of Bonn and offers a stimulating research environment through its research networks, research support, and visitors and doctoral programs. IZA engages in (i) original and internationally competitive research in all fields of labor economics, (ii) development of policy concepts, and (iii) dissemination of research results and concepts to the interested public. The current research program deals with (1) mobility and flexibility of labor, (2) internationalization of labor markets, (3) welfare state and labor market, (4) labor markets in transition countries, (5) the future of labor, (6) evaluation of labor market policies and projects and (7) general labor economics.

IZA Discussion Papers often represent preliminary work and are circulated to encourage discussion. Citation of such a paper should account for its provisional character. A revised version may be available on the IZA website (www.iza.org) or directly from the author. 
IZA Discussion Paper No. 607

October 2002

\section{ABSTRACT}

\section{How Do Firms Redline Workers?*}

In a city where individuals endogenously choose their residential location, firms determine their spatial efficiency wage and a geographical red line beyond which they do not recruit workers. This is because workers experiencing longer commuting trips provide lower effort levels than those residing closer to jobs. By solving simultaneously for the land and labor market equilibrium, we show that there exists a unique market equilibrium that determines the location of all individuals in the city, the land rent, the efficiency wage, the recruitment area and the unemployment level in the economy. This model is able to provide a new mechanism for the spatial mismatch hypothesis by taking the firm's viewpoint. Distance to jobs is harmful not because workers have low information about jobs (search) or because commuting costs are too high but because firms do not hire remote workers.

JEL Classification: J41, R14

Keywords: $\quad$ spatial mismatch, recruitment area, efficiency wage, distance to jobs

Corresponding author:

Yves Zenou

Department of Economics

University of Southamptom

Southampton SO17 1BJ

U.K.

Tel.: (+44) 2380593264

Fax: (+44) 2380593858

Email: yz@soton.ac.uk

* I would like to thank Jan Brueckner for very helpful and stimulating comments. 


\section{Introduction}

The spatial mismatch hypothesis, first formulated by Kain [8], states that black workers, residing in urban segregated areas distant from and poorly connected to major centers of employment growth, face strong geographic barriers to finding and keeping well-paid jobs. In the US context, and perhaps because of discrimination and high prices in the housing market in the suburbs, black workers were forced to stay in the central part of the city, far away from jobs that are nowadays mostly created in the suburbs. So the main contribution of the spatial mismatch hypothesis is to explain the high unemployment rates among blacks via the increasing distance between their residential location and their workplace.

Several papers have tested this hypothesis and have shown that bad job accessibility indeed worsens labor-market outcomes, confirming the spatial mismatch hypothesis (see the surveys by Holzer [6], Kain [9] and Ihlanfeldt and Sjoquist [7]). To provide an economic mechanism for the spatial mismatch hypothesis, this literature has mostly taken the point of view of workers. If indeed workers (especially minorities) reside far away from jobs, then they have poorer information on jobs and their search efficiency is lower than those residing closer to jobs (see in particular Rogers [13], Seater [14], Wasmer and Zenou [18], Smith and Zenou [16]). Others have argued that black workers refuse to take jobs that involve excessively long commutes (Zax and Kain [20], Brueckner and Zenou [2]). In any case, there is a vicious circle: because of

their remote location, the unemployed minorities have difficulties in finding a job, and because they do not find a job, they stay in the ghetto.

The present model offers an alternative explanation by focusing on the point of view of firms. In our model, if firms cannot discriminate on the basis of race by offering different wages for the same job, then they can discriminate on the basis of location by setting higher job rejection rates for those residing far away from jobs, which is frequently the case for ethnic minority workers. This policy is costless for firms since wages are higher than the market clearing wage and are downward rigid. In other words, even though firms have no prejudices against black workers, it is rational for them not to hire black workers if they live too far away (i.e. beyond the recruitment area determined by firms). One of the main ideas developed in this paper is that residential distance to jobs is a key factor in understanding the labor market policy of firms. In particular, workers who reside in remote areas far away from jobs have less chance to obtain a job than those living closer. 
Surprisingly, there have been few attempts to tackle this issue. In the urban literature, geographic redlining (see e.g. Ladd [11] and Lang and Nakamura [12]) involves differentials in mortgage loan supply across neighborhoods or space. In other words, mortgage lenders discriminate on the basis of the location of the property so that people living in redlined areas find difficulties in obtaining loans. More recently, Zenou and Boccard [21] have adopted a different definition of geographic redlining that is linked to the labor market. In their paper, employers exogenously draw a red line between the central part of the city and its suburbs, and discriminate against central residents both in terms of hiring and firing. They show that this policy can have dramatic consequences for inner-city black residents. They do not, however, provide a rationale for this redlining policy but rather assume it and analyze its consequences in terms of labor market outcomes.

In the present paper, we develop an efficiency wage model in which the red line is endogenously determined by firms. Indeed, as in the standard efficiency wage model (Shapiro and Stiglitz [15]), workers can either shirk and produce zero effort or not shirk and produce a strictly positive effort level. The main difference here is that this effort level strongly depends on the distance between jobs and the location of workers: the closer to jobs the workers, the higher the effort. In other words, even if workers decide not to shirk, they will provide a lower effort level if they live far away from jobs because of tiredness due to long commuting trips. Anticipating this behavior, firms then determine the non-shirking condition, the number of workers to hire and the red line beyond which they do not recruit workers.

In this context, by solving simultaneously for the land and labor market equilibrium, we first show that there exists a unique equilibrium that determines the location of all individuals in the city, the land rent, the efficiency wage, the recruitment area and the unemployment level in the economy. We then show that decreasing the unemployment benefit or the commuting cost borne by workers enlarges the recruitment area whereas increasing the monitoring of workers reduces the size of the recruitment areas. Finally, we show that in boom periods (where few jobs are destroyed), firms tend to increase their recruitment area.

The remainder of the paper is organized as follows. Section 2 presents the basic model. In section 3, we develop the land use equilibrium, whereas in section 4, the labor market equilibrium is determined. Finally, section 5 concludes. 


\section{The model}

There is a continuum of workers (employed or unemployed) uniformly distributed along a linear, closed and monocentric city. The density of workers in each location is taken to be $M$. All firms are exogenously located in the Business District (BD hereafter). The BD is a unique employment (and shopping) center located at one end of the linear city. In a centralized city, it corresponds to the central business district, whereas in a completely decentralized city, it represents suburban employment. As will be clear below, what is crucial here is not the location of the $\mathrm{BD}$ but the distance between workers' residential location and their workplace (i.e. the BD). All land is owned by absentee landlords. ${ }^{1}$ Each worker (employed or unemployed) is assumed to consume one unit of land and to be infinitely lived and risk neutral. Workers endogenously decide their optimal place of residence between the BD (i.e. 0) and the city fringe $\left(x_{f}\right)$. There are $N$ identical households and $M$ identical firms. ${ }^{2}$ Among the $N$ households, there are $L$ employed (referred to as the group $L$ ) and $U$ unemployed workers (referred to as the group $U$ ) so that $N=L+U$.

Each individual supplies one unit of labor. As in the standard efficiency wage model (Shapiro and Stiglitz [15]), there are only two possible levels of effort: either the worker shirks, exerting zero effort, $e=0$, and contributing zero to production, or he/she does not shirk, providing full effort. In this case, effort equals $e(x)>0, \forall x \in\left[0, x_{f}\right]$ (with $e(0)=e_{0}>0$ ), contributing $e(x)$ units to production. We assume that $e^{\prime}(x)<0$ and $e^{\prime \prime}(x) \geq 0$ so that the greater the distance to work, the lower the effort level. For remote locations, the marginal difference in effort is quite small. The former assumption is to capture the fact that workers who have longer commuting trips are more tired and are thus less able to provide higher levels of effort than those who reside closer to jobs. To the best of our knowledge, there is no empirical evidence of this negative relationship between effort and distance to jobs, even though this claim is quite plausible and intuitive. We adopt this assumption because our objective is to develop a purely conceptual model that provides a new explanation of the spatial mismatch hypothesis. Our model could then be tested to see how relevant is this hypothesis.

The worker's behavior can be seen as a two-stage decision. First, each worker must decide to shirk or not, depending on their residential location.

\footnotetext{
${ }^{1}$ All theses assumptions are very standard in urban economics. See Fujita [3].

${ }^{2}$ The reason why the density of workers in each location is equal to $M$ the number of firms will become clear in section 4.2.
} 
Since effort is costly, it is clear that the workers who live the closest to jobs will be more inclined to shirk that those residing further away. Thus, contrary to Shapiro and Stiglitz [15] and Zenou and Smith [22] (who introduce space in an efficiency wage model), the moral hazard problem is here locationally dependent. Second, once the worker has decided not to shirk (this is the behavior we will focus on), he/she must decide how much effort he/she provides. This decision is also locationally dependent since we assume that workers who have longer commutes are more tired and provide less effort than those who live closer to jobs.

Observe that the Shapiro-Stiglitz model is a special case of ours when $x=0$, i.e., when workers are all located in one location, the $\mathrm{BD}$, or more generally when space does not affect effort. Observe also that our model is quite different from models with heterogeneous workers (such as Weiss [19], or Gottfries and McCormick [5]) in which firms face an adverse selection problem because they do not observe the effort or the ability of each worker. In the present urban model, firms know the residential location (or the postal address) of each worker and it is assumed that workers cannot misreport their location. There is therefore no adverse selection problem but a moral hazard one.

\section{The land use equilibrium}

Each employed worker goes to the $\mathrm{BD}$ to work and incurs a fixed commuting cost $t$ per unit of distance. He/she also pays a land rent $R(x)$ and earns a wage $w$ (that will be determined in the labor market equilibrium) so that the instantaneous (indirect) utilities of a non-shirker and a shirker residing at a distance $x$ from the $\mathrm{BD}$ are respectively given by: ${ }^{3}$

$$
\begin{gathered}
V_{L}^{N S}(x)=w-e(x)-t x-R(x) \\
V_{L}^{S}(x)=w-t x-R(x)
\end{gathered}
$$

As it should be clear, our formulation does not treat labor-leisure trade offs even though these could affect our results since workers with longer commutes have less leisure than those with less commutes. In order to focus on redlining with risk-neutral workers, we have kept our model as simple as possible with a linear utility function in which effort at work, commuting costs and rent all enter additively and land consumption is unitary regardless of location.

\footnotetext{
${ }^{3}$ The subscript $L$ refers to the employed whereas the subscript $U$ refers to the unemployed. The superscripts $S$ and $N S$ refer respectively to shirkers and non-shirkers.
} 
Concerning the unemployed, they commute less often to the BD since they mainly go there to search for jobs. Thus, they incur a fixed commuting cost of st per unit of distance, with $0<s<1$. For example, $s=1 / 2$ implies that the unemployed make only half as many BD trips as the employed workers. The unemployed workers earn a fixed unemployment benefit $b>0$ exogenously financed by the government and bear spatial costs (the land rent $R(x)$ and the commuting costs). The instantaneous (indirect) utility of an unemployed worker is thus equal to:

$$
V_{U}(x)=b-s t x-R(x)
$$

We are now able to derive the bid rents of all workers in the city. ${ }^{4}$ Since, in equilibrium, the efficiency wage is such that nobody shirks (see the labor market analysis below), we have to determine the land use equilibrium for non-shirker and unemployed workers only. In this context, their bid rents are respectively given by: ${ }^{5}$

$$
\begin{gathered}
\Psi_{L}\left(x, V_{L}\right)=w-e(x)-t x-V_{L} \\
\Psi_{U}\left(x, V_{U}\right)=b-s t x-V_{U}
\end{gathered}
$$

To guarantee that the bid rent curve of the employed workers is downward sloping, we assume throughout that

$$
t+e^{\prime}(x)>0
$$

which means that $t x+e(x)$ is increasing in $x$ despite $e^{\prime}(x)<0$. To understand this, observe that commuting cost $t x$ includes more than just money costs. It also includes these negative effects of a longer commute such as non-workrelated fatigue. So even though people benefit from working less hard on the job as $x$ goes up, the other effects of tiredness (along with the money and time outlay on commuting) make the person worse off overall.

Now, by denoting by $x_{b}$ the recruitment area of firms (the 'red line'), which is equal here to the border between the employed and the unemployed, we easily obtain the following result (see Figure 1 for an illustration):

Proposition 1 Assume $t>-e^{\prime}\left(x_{b}\right) /(1-s)$. Then, in equilibrium, the employed reside close to the $B D$ whereas the unemployed live at the outskirts of the city.

\footnotetext{
${ }^{4}$ The bid rent is a standard concept in urban economics. It indicates the maximum land rent that a type $i=L, U$ worker located at a distance $x$ from the CBD is ready to pay in order to achieve the utility level $V_{i}$.

${ }^{5}$ We drop the superscript $N S$ when there is no ambiguity.
} 
Proof. See the Appendix.

Observe that the condition $t>-e^{\prime}\left(x_{b}\right) /(1-s)$ is a more stringent version of (6), and is not implied by it. Let us now give the intuition of Proposition 1. An increase in distance $x$ has offsetting effects on employed workers: they pay higher commuting costs but lower effort is exerted on the job. The net effect is thus less than the pure commuting cost effect, and the question is whether this net effect is stronger than the shrunken commuting cost effect for unemployed workers, which is smaller than that of the employed worker because $s<1$. In this context, when the commuting cost $t$ is high enough, the employed workers reside close to jobs by outbidding the unemployed.

Observe that if the sign of the above inequality is reversed, i.e. $t<$ $-e^{\prime}\left(x_{b}\right) /(1-s)$, then we have the opposite spatial pattern in which the unemployed reside close to jobs. Since the aim of this paper is to propose a new mechanism of the spatial mismatch hypothesis, we only focus on the equilibrium where the unemployed are far away from jobs. This spatial pattern is consistent with several US 'edge'cities (like for example Houston, Los Angeles or Phoenix; see Glaeser, Kahn and Rappaport [4]) where jobs are located in the suburbs and most unemployed in the city-center where land rents are quite low. Our equilibrium does capture the spatial pattern of these cities since our $\mathrm{BD}$ can be viewed as a suburban business district and the unemployed reside in low-rent locations far away from jobs.

\section{[Insert Figure 1 here]}

Let us now give a formal definition of the land use equilibrium taking the labor market outcomes ( $w$ and $L)$ as parameters. By assuming, without loss of generality, that the opportunity cost of urban land is zero, we have:

Definition 1 The land use equilibrium is a vector $\left(x_{b}, x_{f}, V_{L}, V_{U}\right)$ such that:

$$
\begin{gathered}
\int_{0}^{x_{b}} M d x=L \\
\int_{x_{b}}^{x_{f}} M d x=N-L \\
\Psi_{L}\left(x_{b}, V_{L}\right)=\Psi_{U}\left(x_{b}, V_{U}\right) \\
\Psi_{U}\left(x_{f}, V_{U}\right)=0
\end{gathered}
$$

Equations (7)-(8) are the population constraints for a linear city in which workers consume one unit of land and the density of workers is equal to 1 . 
Equations (9)-(10) reflect the equilibrium conditions in the land market that ensure that the land rent is continuous (see Figure 1). Solving (7)-(10) yields:

$$
\begin{gathered}
x_{b}=\frac{L}{M} \\
x_{f}=\frac{N}{M} \\
V_{U}=b-s t \frac{N}{M} \\
V_{L}=w-e\left(x_{b}\right)-t x_{b}-s t\left(\frac{N}{M}-x_{b}\right)
\end{gathered}
$$

Observe that, in equilibrium, all the unemployed obtain $V_{U}$ and all the employed $V_{L}$, whatever their location. This is because mobility is costless and the land rent compensate workers for different locations. By plugging (13) and (14) into (4) and (5), we easily obtain the land rent equilibrium $R(x)$. It is given by:

$$
R(x)= \begin{cases}t\left[(1-s) x_{b}+s \frac{N}{M}\right]+e\left(x_{b}\right)-[e(x)+t x] & \text { for } 0 \leq x \leq x_{b} \\ s t\left(\frac{N}{M}-x\right) & \text { for } x_{b}<x \leq \frac{N}{M} \\ 0 & \text { for } x>\frac{N}{M}\end{cases}
$$

Observe also that equation (11) defines a one-to-one relationship between $x_{b}$ and $L$. So, we can solve the labor equilibrium either in terms of $x_{b}$ or $L$. Since the focus of this paper is on redlining, we have chosen to express everything in terms of $x_{b}$ in order to determine the optimal recruitment area $x_{b}$ chosen by firms.

\section{The labor market equilibrium}

We can now give a formal definition of equilibrium in the labor market. This definition incorporates the outcomes of the land use equilibrium (equations (11)-(14)) so that the land use equilibrium and the labor market equilibrium are solved for simultaneously. We have:

Definition 2 A (steady-state) labor market equilibrium is a vector $\left(x_{b}^{*}, w^{*}, L^{*}\right)$ such that all agents (workers and firms) maximize their respective objective function, i.e. this triple is determined by a wage-setting mechanism, a steadystate condition on unemployment and an optimal recruitment area decision. 


\subsection{The efficiency wage}

In the labor market, firms cannot perfectly monitor workers so that there is a probability of being detected shirking, denoted by $\theta$. If a worker is caught shirking, he/she is automatically fired. Time is continuous and workers live forever. We assume that changes in employment status are governed by a Poisson process in which $a$ is the (endogenous) job acquisition rate and $\delta$ the (exogenous) destruction rate. Let us denote by $r$ the common discount rate of all workers. Then, the standard steady-state Bellman equations for the non-shirkers, the shirkers and the unemployed are given by: ${ }^{6}$

$$
\begin{gathered}
r I_{L}^{N S}=V_{L}^{N S}-\delta\left(I_{L}^{N S}-I_{U}\right) \\
r I_{L}^{S}(x)=V_{L}^{S}(x)-(\delta+\theta)\left(I_{L}^{S}(x)-I_{U}\right) \\
r I_{U}=V_{U}+a\left(I_{L}^{N S}-I_{U}\right)
\end{gathered}
$$

where $I_{L}^{N S}, I_{L}^{S}$ and $I_{U}$ respectively represent the expected lifetime utility of a non-shirker, a shirker and an unemployed worker, $V_{L}^{N S}=V_{L}, V_{L}^{S}(x)=$ $V_{L}+e(x)$, where $V_{U}$ and $V_{L}$ are defined by (13) and (14). Equation (16) says that a non-shirker obtain today $V_{L}^{N S}$ but can lose his/her job with a probability $\delta$ and then obtain a negative surplus of $-\left(I_{L}^{N S}-I_{U}\right)$. For $(17)$, we have the same interpretation except the fact that a shirker can lose his/her job for two reasons: either the job is destroyed or he/she is caught shirking. Equation (18) has a similar interpretation.

Let now determine the wage setting. In the standard model (Shapiro and Stiglitz [15], Zenou and Smith [22]), the efficiency wage must be set to make workers indifferent between shirking and not shirking. However, in the present model, the utility of shirkers is not constant over locations (see (17)) whereas it is constant for non-shirkers (see (16)). It is in fact easy to see that the utility of shirkers increases as $x$, the distance to the BD, decreases. ${ }^{7}$ This implies, in particular, that the highest utility that a shirker can reach is at the $x=0$ (the $\mathrm{BD}$ ) and the lowest is at $x=x_{b}$. As a result, the efficiency wage must be set to make workers indifferent between shirking at location $x=0$ and not

\footnotetext{
${ }^{6}$ See the Appendix for the derivation of equations (16), (17) and (18).

${ }^{7}$ The intuition is straightforward. Since the land rent compensates for both commuting costs and effort levels, then shirkers, who do not provide effort, have a higher utility when residing closer to the BD (since their commuting costs are lower). Formally, using (2) and (15), we have:

$$
\frac{\partial V_{L}^{S}}{\partial x}=-t-R^{\prime}(x)=-t+e^{\prime}(x)+t=e^{\prime}(x)<0
$$
}


shirking since if the worker at $x=0$ does not shirk, then all workers located further away will not shirk. In other words, the condition that determines the efficiency wage is given by $I_{L}^{N S}=I_{L}^{S}(0)=I_{L}$. By observing from (2) that $V_{L}^{S}(0)=w-R(0)$ and by using (15) and (17), we obtain:

$$
r I_{L}^{S}(0)=w-e\left(x_{b}\right)+e_{0}-t x_{b}-s t\left(N / M-x_{b}\right)-(\delta+\theta)\left(I_{L}^{S}(0)-I_{U}\right)
$$

Now, by plugging (14) into (16), and by using the resulting equation and (19), the condition $I_{L}^{N S}=I_{L}^{S}(0)=I_{L}$ can be written as:

$$
I_{L}-I_{U}=\frac{e_{0}}{\theta}
$$

where, as defined above, $e(0) \equiv e_{0}$. This highlights the nature of our efficiency wage. The surplus of being employed is strictly positive and does not depend on space. As in Shapiro and Stiglitz [15] and Zenou and Smith [22], this a pure incentive effect to deter shirking. This surplus only depends on the monitoring technology, since more monitoring implies less shirking, and on the effort level provided by the worker located at $x=0$ (the highest effort level among all workers).

Now using (14), equation (16) can be written as:

$$
\begin{aligned}
w & =e\left(x_{b}\right)+r I_{L}+\delta\left(I_{L}-I_{U}\right)+t x_{b}+s t\left(N / M-x_{b}\right) \\
& =e\left(x_{b}\right)+r I_{U}+(\delta+r)\left(I_{L}-I_{U}\right)+t x_{b}+s t\left(N / M-x_{b}\right)
\end{aligned}
$$

Furthermore, using (18) and (20), this can be rewritten as:

$$
w=e\left(x_{b}\right)+\frac{e_{0}}{\theta}(a+\delta+r)+V_{U}+t x_{b}+s t\left(N / M-x_{b}\right)
$$

which by using (13) yields:

$$
w=b+e\left(x_{b}\right)+\frac{e_{0}}{\theta}(a+\delta+r)+(1-s) t x_{b}
$$

Finally, at the steady state, flows out of unemployment equal flows into unemployment, i.e.

$$
a(N-L)=\delta L
$$

so that the efficiency wage is finally given by:

$$
w=b+e\left(x_{b}\right)+\frac{e_{0}}{\theta}\left(\frac{\delta N}{N-M x_{b}}+r\right)+(1-s) t x_{b}
$$

This equation (21) is referred to as the Urban No-Shirking Condition (UNSC hereafter). We have the standard comparative-statics effects of the 
efficiency wage without space (Shapiro-Stiglitz [15]) and with space (Zenou and Smith [22], Brueckner and Zenou [1]). Indeed, an increase in the unemployment benefit $b$, the job destruction rate $\delta$, the discount rate $r$, or the commuting cost $t$, or a decrease in the monitoring rate $\theta$ or the unemployed BD-trips $s$ raise the efficiency wage. For the non-spatial elements, $b, \delta, r$ and $\theta$, the reason is that firms have to increase their wage to meet the UNSC so that no worker will shirk. For the spatial elements, $t$ and $s$, firms have to compensate their employed workers for spatial costs. Indeed, when setting their (efficiency) wage, firms must compensate the spatial cost differential between the employed and the unemployed. For the employed and the unemployed who both live at $x_{b}$ (this is the redline that will be optimally determined by firms in the next section) this differential is exactly equal to $(1-s) t x_{b}$ because they pay the same land rent. Now, since mobility is costless, all the employed and unemployed workers obtain respectively the same utility level whatever their location. Therefore, the spatial cost differential between any employed and unemployed worker is equal to $(1-s) t x_{b}$.

All these elements imply that the efficiency wage has two roles: to prevent shirking (incentive component) and to ensure that workers are locationally indifferent (spatial compensation component). The key relation here is the interaction between the effort function $e(\cdot)$ and the location of workers. What is crucial in this wage setting process is that, even if firms observe the workers' location, we do not allow them to offer different wages according to residence location. This is a legal constraint based on the fact that, in the real world, one never observes firms that discriminate across identical workers according to their location. There are some firms (especially in Japan) that do subsidize commuting costs but do not set wages that are location dependent.

Our setting thus implies that there is a fundamental asymmetry between workers and firms. All workers get the same efficiency wage whatever their location. However, they do not contribute the same level of production because effort decreases with distance to jobs. In other words, even though the wage cost is location independent the production is not. This implies that the per-worker profit decreases with distance to jobs. The next natural step of our analysis (which will be done in the next section) is thus to calculate the per-worker profit for each firm and to determine the red line beyond which firms do not hire workers. It is this asymmetry between workers and firms that makes the redline story interesting. If wages were location dependent, then there would be no redlining (at least from the firms' perspective) since 
the per-worker profit would be location independent and firms would just pay wages contingent on the effort level provided.

The interesting implication of this paper is that it can explain the spatial mismatch hypothesis from a very different viewpoint. Distance to jobs is harmful not because workers have low information about jobs (search) or because commuting costs are too high but because firms do not hire remote workers. Indeed, if firms cannot discriminate in terms of location (make wages location dependent), they do anticipate that remote workers provide lower effort level. So they stop recruiting workers residing too far away.

In order to determine the recruitment area $x_{b}$, it is crucial to understand the relation between the efficiency wage and $x_{b}$. The following proposition gives the properties of this relation:

Proposition 2 The properties of the efficiency wage $w$ defined by (21) are the following:

(i) The efficiency wage $w$ is increasing and convex with respect to $x_{b}$;

(ii) Its limit when $x_{b}$ tends to $N / M\left(=x_{f}\right)$ is given by:

$$
\lim _{x_{b} \rightarrow N / M} w=+\infty
$$

(iii) When $x_{b}=0$, we have: $w=b+e_{0}+\frac{e_{0}}{\theta}(\delta+r)>0$.

Proof. See the Appendix.

The following comments are in order. First, the key result here is the positive relation between $w$ and $x_{b}$. Indeed, there are two effects raising the wage when $x_{b}$ rises, the reduction in unemployment and the need to compensate for the higher commuting costs of the marginal employed worker. There is one effect tending to reduce the wage, namely, the lower the effort level of the marginal worker. However, because we focus on a spatial structure in which the employed have steeper bid rents than the unemployed, so that $t$ is large enough (see Proposition 1), the first two effects dominate the third one and thus the relationship between $x_{b}$ and $w$ is always positive.

Second, (ii) in Proposition 2 is a standard result that states that full employment is not compatible with efficiency wages. Indeed, if this were not true, then firms could always set an efficiency wage at the full employment level. In this context, workers would always shirk because, even if they were caught shirking, they could always find a new job. This is in contradiction with the nature of efficiency wages. Finally, the last result ( $i i i)$ of Proposition 2 just states that, at zero employment level, firms still set a positive (efficiency) wage. 


\subsection{The determination of the recruitment area}

There are $M$ identical firms $(j=1, \ldots, M)$ in the economy. All firms produce the same composite good and sell it at a fixed market price $p$ (this good is taken as the numeraire so that its price $p$ is set to 1 ). We assume that all jobs are obtained through an employment agency that coordinates workers in such a way that each firm employs only one worker at each location. ${ }^{8}$ Since all firms and workers are (ex ante) identical and since the density of workers at each location is $M$, we focus on a symmetric equilibrium in which each firm sets the same $x_{b}$. This is quite reasonable since, ex ante (before location), all workers are equally productive (location is not a characteristic of a worker), and, ex post (once located), they are all indifferent to work in any of the $M$ firms since all firms are located at 0 and offer the same wage $w$. In this context, since all firms are identical, the employment level in each firm $j$ is equal to: $l_{j}=l=L / M=x_{b}$.

We are now able to calculate the total production (or effort) level provided in each firm. It is given by:

$$
\bar{e}=\int_{0}^{x_{b}} e(x) d x
$$

It is interesting to observe that the average production (or effort) in each firm is given by $e^{a v}=\frac{1}{x_{b}} \int_{0}^{x_{b}} e(x) d x$, with

$$
\frac{\partial e^{a v}}{\partial x_{b}}=-\frac{1}{x_{b}}\left[\bar{e}-e\left(x_{b}\right)\right]<0
$$

In words, a larger recruitment area decreases the average effort level in each firm since new hired workers produce less effort because they live further away.

Each firm $j=1, \ldots, M$ has the same production function given by $f(\bar{e})$. We assume that $f(\cdot)$ is twice differentiable with $f(0)=0, f^{\prime}(\bar{e})>0$ and $f^{\prime \prime}(\bar{e}) \leq 0$, and satisfies the Inada conditions, i.e. $f^{\prime}(0)=+\infty$ and $f^{\prime}(+\infty)=0$. In this context, each firm chooses its recruitment area $x_{b}$ that maximizes its profit by

\footnotetext{
${ }^{8}$ In the first period, the timing is as follows. All $N$ workers apply for a job in the employment agency and only $L$ of them obtain a job and locate somewhere in the city (since they are indifferent between all locations between 0 and $x_{b}$ ). Then, the employment agency allocates workers to firms in such a way that each firm recruits one worker at each location. This is true at any moment of time (and in particular in the steady state) since, at each period, some workers with different locations lose their job and new workers obtain a job and reside somewhere in the city between 0 and $x_{b}$. Then again, the employment agency allocates these new workers to firms in such a way that each firm (those who has lost workers) employs only one worker at each location.
} 
taking the efficiency wage as parametric. Formally,

$$
\max _{x_{b}}\left[f(\bar{e})-w x_{b}\right]
$$

The first order condition yields: ${ }^{9}$

$$
f^{\prime}(\bar{e})=\frac{w}{e\left(x_{b}\right)}
$$

This equation states that the optimal recruitment area $x_{b}$ chosen by each firm is such that the marginal productivity of workers is equal to their cost per efficiency unit of labor. This determines the labor demand in each firm. Now, since all firms are identical, by symmetry, all $x_{b}$ are equal and given by (23). Since there are $M$ firms in the economy, the aggregate production function $F(M \bar{e})=M f(\bar{e})$ and the total labor demand in the economy is equal to $L=M x_{b}$. The aggregate equivalent of (23) is thus given by: ${ }^{10}$

$$
F^{\prime}(M \bar{e})=\frac{w}{e\left(x_{b}\right)}
$$

It is easy to verify that the labor demand $x_{b}$ is downward sloping in the plane $\left(x_{b}, w\right)$. Indeed, by totally differentiating $(24)$, we easily obtain:

$$
\frac{\partial w}{\partial x_{b}}=F^{\prime \prime}(M \bar{e}) M\left[e\left(x_{b}\right)\right]^{2}+F^{\prime}(M \bar{e}) e^{\prime}\left(x_{b}\right)<0
$$

\subsection{The steady-state equilibrium}

Since we know how $w$ and $x_{b}$ are related, we have:

Proposition 3 Assume that $t>-e^{\prime}\left(x_{b}\right) /(1-s)$. Then, there exists a unique labor market equilibrium in which the equilibrium recruitment area $x_{b}^{*}$ is (implicitly) defined by

$$
e\left(x_{b}^{*}\right) F^{\prime}\left(M \int_{0}^{x_{b}^{*}} e(x) d x\right)
$$

${ }^{9}$ The second order condition is given by

$$
f^{\prime \prime}(\bar{e})\left[e\left(x_{b}\right)\right]^{2}+f^{\prime}(\bar{e}) e^{\prime}\left(x_{b}\right)<0
$$

${ }^{10}$ Observe that since $F(M \bar{e})=M f(\bar{e})$, we have

$$
\frac{\partial F(M \bar{e})}{\partial x_{b}}=M e\left(x_{b}\right) F^{\prime}(M \bar{e})=M e\left(x_{b}\right) f^{\prime}(\bar{e})
$$

or equivalently

$$
F^{\prime}(M \bar{e})=f^{\prime}(\bar{e})
$$




$$
=b+e\left(x_{b}^{*}\right)+\frac{e_{0}}{\theta}\left(\frac{\delta N}{N-M x_{b}^{*}}+r\right)+(1-s) t x_{b}^{*}
$$

the equilibrium efficiency wage $w^{*}$ by (21) and the equilibrium employment level $L^{*}$ by

$$
L^{*}=M x_{b}^{*}
$$

Proof. See the Appendix.

This result gives a unique recruitment area $x_{b}^{*}$ and a unique efficiency wage $w^{*}$. Using (11), we obtain the equilibrium employment level in the economy since $L^{*}=M x_{b}^{*}$. We can then deduce the equilibrium level of unemployment $U^{*}=N-L^{*}$. Observe that the recruitment area $x_{b}^{*}$ affects both the quality of the workers and the efficiency wage. Indeed, when $x_{b}^{*}$ increases, the average effort level in each firm decreases (see (22)) but the equilibrium efficiency wage $w^{*}$ increases (see Proposition 2). The latter result is true only if the effort of the workers is not too sensitive to the length of the recruitment area. Observe also that, as in the standard efficiency wage model, urban unemployment is involuntary. Indeed, even though the unemployed workers are ready to work for a lower wage in order to get a job, firms will never accept this offer because the UNSC will not be respected and all workers will shirk. Therefore it is the presence of high and sticky wages that create (involuntary) unemployment. In this context, taking space into account increases the level of unemployment since spatial efficiency wages are higher than in the absence of commuting costs (as for example in Shapiro and Stiglitz [15]).

Observe finally that, even by keeping the location-dependent effort hypothesis, we could not obtain most of our results in a perfect competition environment (no unemployment) or in a minimum wage model (unemployment with no shirking). The virtue of the present model with shirking is that redlining is a necessary feature of equilibrium. In other words, there has to be some unemployment in order for shirking to be discouraged.

Let us now investigate the properties of the equilibrium. We have:

Proposition 4 Assume $t>-e^{\prime}\left(x_{b}\right) /(1-s)$. Then, the equilibrium recruitment area $x_{b}^{*}$ is increasing in the monitoring rate $\theta$, in the percentage of $B D$ trips of the unemployed $s$ and in the size of the active population $N$, but it is decreasing in the unemployment benefit $b$, the unit commuting cost $t$, the effort level $e_{0}$ provided at location $x=0$, the discount rate $r$ and the job destruction rate $\delta$. For the equilibrium wage $w^{*}$, we have exactly the reverse effects.

Proof. See the Appendix. 
The following comments are in order. First, a rise in the unemployment benefit shifts upward the UNSC since, at each recruitment area level $x_{b}$ (or equivalently employment level), the efficiency wage must increase to deter shirking. This is the standard outside option effect generated by the unemployment benefit. Because wages are higher, it is more costly for firms to hire new workers since they are less productive (they live further away from jobs) and cost more. As a result, firms reduce their recruitment area. In other words, when $b$ increases, firms employ workers who live closer to jobs that are therefore more productive but pay them more. Second, we have the opposite result concerning the monitoring technology $\theta$. Indeed, if firms monitor their workers more, the efficiency wage is lower so that firms extend their recruitment area. Third, increasing the unit commuting cost $t$ borne by workers or decreasing the number of BD-trips $s$ reduces the recruitment area $x_{b}$. The intuition is exactly the same as for $b$ but here the efficiency wage must increase not to deter shirking but to spatially compensate employed workers (this is the compensation effect mentioned above). Fourth, when the maximum effort provided in the city, $e_{0}$, increases, the efficiency wage increases because globally all workers provide more effort (a rise in the intercept $e_{0}$ shifts upward the non-shirking effort curve $e(x)$ ). As a result, firms hires less workers and thus reduce $x_{b}$. Finally, when there are more technological shocks in the economy so that jobs are destroyed more often ( $\delta$ increases), then firms have to increase their wages to deter shirking and thus to reduce their recruitment area.

\section{Conclusion}

We have developed a model in which firms set efficiency wages and determine their optimal recruitment area. We have shown that it is rational for them not to hire workers residing in remote areas because their productivity is lower than those residing closer to jobs. This is because workers who experience longer commuting trips are more tired and thus less efficient than those who have shorter journey-to-work patterns.

Our main results are the following. We first show that there exists a unique equilibrium in which land and labor market equilibria are solved for simultaneously. We then show that labor market as well as spatial parameters do influence the equilibrium recruitment area set by firms. In particular, a rise in the unemployment benefit or in the commuting cost increases wages and reduces this recruitment area. Finally, our model can shed some light on the 
spatial mismatch hypothesis that puts forward distance to jobs as the main culprit for the high unemployment rates among ethnic minorities. Since the latter tend to reside far away from jobs, firms do not hire them, not because employers are prejudiced, but because their effort level is too low.

\section{References}

[1] J.K. Brueckner and Y. Zenou, Harris-Todaro models with a land market, Regional Science and Urban Economics, 29, 317-339 (1999).

[2] J.K. Brueckner and Y. Zenou, Space and unemployment: the labormarket effects of spatial mismatch, Journal of Labor Economics, forthcoming.

[3] M. Fujita, "Urban Economic Theory," Cambridge University Press, Cambridge (1989).

[4] E.L. Glaeser, M. Kahn and J. Rappaport, Why do the poor live in cities?, NBER Working Paper Series No. 7636 (2000).

[5] N. Gottfries and B. McCormick, Discrimination and open unemployment in a segmented labour market, European Economic Review, 39, 1-15 (1995).

[6] H. J. Holzer, The spatial mismatch hypothesis: What has the evidence shown?, Urban Studies, 28, 105-122 (1991).

[7] K.R. Ihlanfeldt and D.L. Sjoquist, The spatial mismatch hypothesis: a review of recent studies and their implications for welfare reform, Housing Policy Debate, 9, 849-892 (1998).

[8] J.F. Kain, Housing segregation, negro employment, and Metropolitan decentralization, Quarterly Journal of Economics, 82, 175-197 (1968).

[9] J. F. Kain, The spatial mismatch hypothesis: Three decades later, Housing Policy Debate, 3, 371-460 (1992).

[10] V.G. Kulkarni, "Modeling and Analysis of Stochastic Processes," Chapman \& Hall, London (1995).

[11] H.F. Ladd, Evidence on discrimination in mortgage lending, Journal of Economic Perspectives, 12, 41-62 (1998). 
[12] W.W. Lang and L.I. Nakamura, A model of redlining, Journal of Urban Economics, 33, 223-234 (1993).

[13] C.L. Rogers, Job search and unemployment duration: implications for the spatial mismatch hypothesis, Journal of Urban Economics, 42, 109132 (1997).

[14] J. Seater, Job search and vacancy contacts, American Economic Review, 69, 411-419 (1979).

[15] C. Shapiro and J. Stiglitz, Equilibrium unemployment as a worker discipline device, American Economic Review, 74, 433-444 (1984).

[16] T.E. Smith and Y. Zenou, "Spatial mismatch, search effort and workers' location", Unpublished manuscript, University of Southampton (2002).

[17] N.L. Stokey and R.E. Lucas, "Recursive Methods in Economic Dynamics", Harvard University Press, Cambridge (1989).

[18] E. Wasmer and Y. Zenou, "Does city-structure affect job search and welfare?", Journal of Urban Economics (2002).

[19] A.Weiss, Job queues and layoffs in labor markets with flexible wages, Journal of Political Economy, 88, 526-538 (1980).

[20] J. Zax and J.F. Kain, Moving to the suburbs: do relocating companies leave their black employees behind?, Journal of Labor Economics, 14, 472-493 (1996).

[21] Y. Zenou and N. Boccard, Racial discrimination and redlining in cities, Journal of Urban Economics, 48, 260-285 (2000).

[22] Y. Zenou and T.E. Smith, Efficiency wages, involuntary unemployment and urban spatial structure, Regional Science and Urban Economics, 25, 821-845 (1995). 


\section{APPENDIX}

\section{Proof of Proposition 1}

By differentiating (4) and (5), we obtain:

$$
\begin{gathered}
\frac{\partial \Psi_{L}\left(x, v_{E}\right)}{\partial x}=-\left[e^{\prime}(x)+t\right] \\
\frac{\partial \Psi_{U}\left(x, v_{U}\right)}{\partial x}=-s t<0
\end{gathered}
$$

Using (6), it is easy to see that all bid rents in the city are decreasing from the center to the periphery. We would like now to show that the employed workers

reside close to the $\mathrm{BD}$ and the unemployed further away. For that, we need to show that, at the border $x_{b}$ between the employed and the unemployed, we have:

$$
-\left.\frac{\partial \Psi_{L}\left(x, v_{E}\right)}{\partial x}\right|_{x=x_{b}}=e^{\prime}\left(x_{b}\right)+t>s t=-\left.\frac{\partial \Psi_{U}\left(x, v_{U}\right)}{\partial x}\right|_{x=x_{b}}
$$

This is true if and only if $t>-e^{\prime}\left(x_{b}\right) /(1-s)$.

\section{Derivation of equations (16), (17) and (18)}

The derivation of (16) and (18) are as follows. As stated above, changes in employment status are assumed to be governed by a Poisson (or Markov) process with two states: 'employed' and 'unemployed'. The key feature of these stochastic processes is that the duration time spent in each state is a random variable with exponential distribution. More precisely, if we denote by $\tau_{\delta}$ and $\tau_{a}$ the (random) non-shirking employment and unemployment duration times, then

$$
\begin{aligned}
& F\left(\tau_{\delta}\right)=\mathbb{P}\left[\tau_{\delta}<t\right]=1-e^{-\delta \tau_{\delta}} \\
& F\left(\tau_{a}\right)=\mathbb{P}\left[\tau_{a}<t\right]=1-e^{-a \tau_{a}}
\end{aligned}
$$

This implies that the density functions are given by:

$$
\begin{aligned}
& f\left(\tau_{\delta}\right)=\delta e^{-\delta \tau_{\delta}} \\
& f\left(\tau_{a}\right)=a e^{-a \tau_{a}}
\end{aligned}
$$


Taking account of these waiting durations and by using the standard tools of dynamic programming (see e.g. Stockey and Lucas [17]), the expected lifetimeutilities of a non-shirker employed worker $I_{L}^{N S}$ and of an unemployed worker $I_{U}$ can then be written as:

$$
\begin{aligned}
& I_{L}^{N S}=\mathbb{E}\left[\int_{0}^{\tau_{\delta}} w e^{-r t} d t+e^{-r \tau_{\delta}} I_{U}\right] \\
& I_{U}=\mathbb{E}\left[\int_{0}^{\tau_{a}} b e^{-r t} d t+e^{-r \tau_{a}} I_{L}^{N S}\right]
\end{aligned}
$$

where $\mathbb{E}[\cdot]$ is the expectation operator. By developing these expressions, we have:

$$
\begin{aligned}
& I_{L}^{N S}=\int_{0}^{+\infty}\left[\int_{0}^{\tau_{\delta}} w e^{-r t} d t\right] f\left(\tau_{\delta}\right) d \tau_{\delta}+I_{U} \int_{0}^{+\infty} e^{-r \tau_{\delta}} f\left(\tau_{\delta}\right) d \tau_{\delta} \\
& I_{U}=\int_{0}^{+\infty}\left[\int_{0}^{\tau_{a}} b e^{-r t} d t\right] f\left(\tau_{a}\right) d \tau_{a}+I_{L}^{N S} \int_{0}^{+\infty} e^{-r \tau_{a}} f\left(\tau_{a}\right) d \tau_{a}
\end{aligned}
$$

Finally, by using the values of the two density functions above $f\left(\tau_{a}\right)$ and $f\left(\tau_{\delta}\right)$, and after some calculations, we obtain (16) and (18) respectively.

The derivation of (17) is a little bit more complicated since, when employed, a shirker can lose his/her job because either he/has been caught shirking or the job has been destroyed. By denoting by $\tau_{\theta}$ the (random) length of time until the next control of shirking occurs, this implies that $\tau_{a}$ is still the (random) unemployment duration time whereas $\min \left(\tau_{\delta}, \tau_{\theta}\right)$ is now the employment duration time for a shirker. Since we know (see for example Kulkarni [10], ch. 5) that $\min \left(\tau_{\delta}, \tau_{\theta}\right)$ is a random variable characterized by an exponential distribution of parameter $\delta+\theta$, i.e.

$$
F\left(\min \left(\tau_{\delta}, \tau_{\theta}\right)\right)=\mathbb{P}\left[\min \left(\tau_{\delta}, \tau_{\theta}\right)<t\right]=1-e^{-(\delta+\theta) \min \left(\tau_{\delta}, \tau_{\theta}\right)}
$$

then the expected lifetime-utility of a shirker $I_{L}^{S}$ is equal to:

$$
I_{L}^{S}=\mathbb{E}\left[\int_{0}^{\min \left(\tau_{\delta}, \tau_{\theta}\right)} w e^{-r t} d t+e^{-r \min \left(\tau_{\delta}, \tau_{\theta}\right)} I_{U}\right]
$$

By doing exactly the same kind of manipulations as above, we obtain (17). 


\section{Proof of Proposition 2}

(i) We have:

$$
\frac{\partial w}{\partial x_{b}}=e^{\prime}\left(x_{b}\right)+\frac{e_{0}}{\theta} \frac{\delta N M}{\left(N-M x_{b}\right)^{2}}+(1-s) t
$$

From Proposition 1, we know that $(1-s) t>-e^{\prime}\left(x_{b}\right)$, which implies that

$$
\frac{\partial w}{\partial x_{b}}>0
$$

Furthermore, we have:

$$
\frac{\partial^{2} w}{\partial x_{b}^{2}}=e^{\prime \prime}\left(x_{b}\right)+\frac{e_{0}}{\theta} \frac{2 \delta N M^{2}}{\left(N-M x_{b}\right)^{3}}>0
$$

(ii) and (iii) : Using (21), these conclusions are straightforward.

\section{Proof of Proposition 3}

On one hand, from Proposition 2, we know that $w$ is an increasing and convex function of $x_{b}$, whose intercept is a positive constant $\left(b+e_{0}+e_{0}(\delta+\right.$ $r)(\theta>0)$ and has an asymptote at $x_{b}=x_{f}=N / M$. On the other, from (25), the labor demand (24) is decreasing in the plane $\left(x_{b}, w\right)$ and $F^{\prime}(0)=+\infty$ and $\lim _{L \rightarrow+\infty} F^{\prime}(\cdot)=0$ (Inada conditions). In particular, $\lim _{L \rightarrow+\infty} F^{\prime}(\cdot)=0$ means that $F^{\prime}\left(x_{b}=N / M\right)$ is equal to a positive constant. In this context, the two curves cross each other only once and there exists thus a unique labor market equilibrium with a unique value of $x_{b}^{*}$ and $w^{*}$ and thus $L^{*}$.

\section{Proof of Proposition 4}

The two equilibrium equations (21) and (24) can be written as follows:

$$
\begin{aligned}
\Gamma & =w-b-e\left(x_{b}\right)-\frac{e_{0}}{\theta}\left(\frac{\delta N}{N-M x_{b}}+r\right)-(1-s) t x_{b}=0 \\
\Phi & =w-e\left(x_{b}\right) F^{\prime}\left(M \int_{0}^{x_{b}} e(x) d x\right)=0
\end{aligned}
$$


By totally differentiating these two equations, we obtain:

$$
\mathbf{A}\left(\begin{array}{c}
d w^{*} \\
d x_{b}^{*}
\end{array}\right)=\mathbf{B}\left(\begin{array}{c}
d b \\
d s \\
d t \\
d e_{0} \\
d \theta \\
d r \\
d \delta \\
d N
\end{array}\right)
$$

where, by using $t>-e^{\prime}\left(x_{b}\right) /(1-s)$,

$$
\mathbf{A}=\left(\begin{array}{ll}
+ & - \\
+ & +
\end{array}\right)
$$

and

$$
\mathbf{B}=\left(\begin{array}{cccccccc}
+ & - & + & + & - & + & + & - \\
0 & 0 & 0 & 0 & 0 & 0 & 0 & 0
\end{array}\right)
$$

Since the determinant of $\mathbf{A}$ is strictly positive, we can apply the Cramer rule.

We easily obtain:

$$
\begin{aligned}
& \frac{\partial w^{*}}{\partial b}>0 \quad \frac{\partial w^{*}}{\partial s}<0 \quad \frac{\partial w^{*}}{\partial t}>0 \quad \frac{\partial w^{*}}{\partial e_{0}}>0 \quad \frac{\partial w^{*}}{\partial \theta}<0 \quad \frac{\partial w^{*}}{\partial r}>0 \quad \frac{\partial w^{*}}{\partial \delta}>0 \quad \frac{\partial w^{*}}{\partial N}<0 \\
& \frac{\partial x_{b}^{*}}{\partial b}<0 \quad \frac{\partial x_{b}^{*}}{\partial s}>0 \quad \frac{\partial x_{b}^{*}}{\partial t}<0 \quad \frac{\partial x_{b}^{*}}{\partial e_{0}}<0 \quad \frac{\partial x_{b}^{*}}{\partial \theta}>0 \quad \frac{\partial x_{b}^{*}}{\partial r}<0 \quad \frac{\partial x_{b}^{*}}{\partial \delta}<0 \quad \frac{\partial x_{b}^{*}}{\partial N}>0
\end{aligned}
$$


$\mathrm{R}(\mathrm{x})$

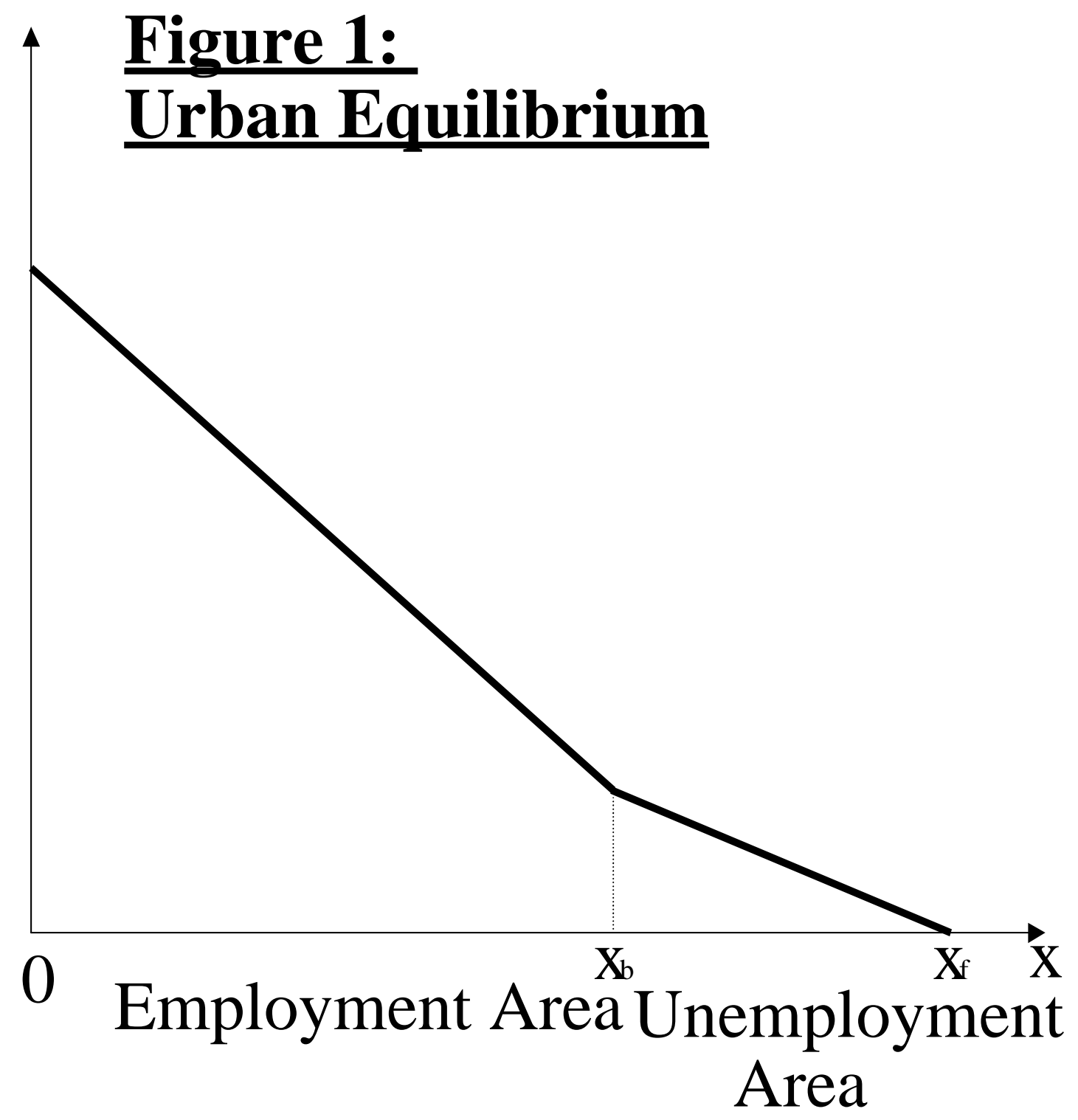




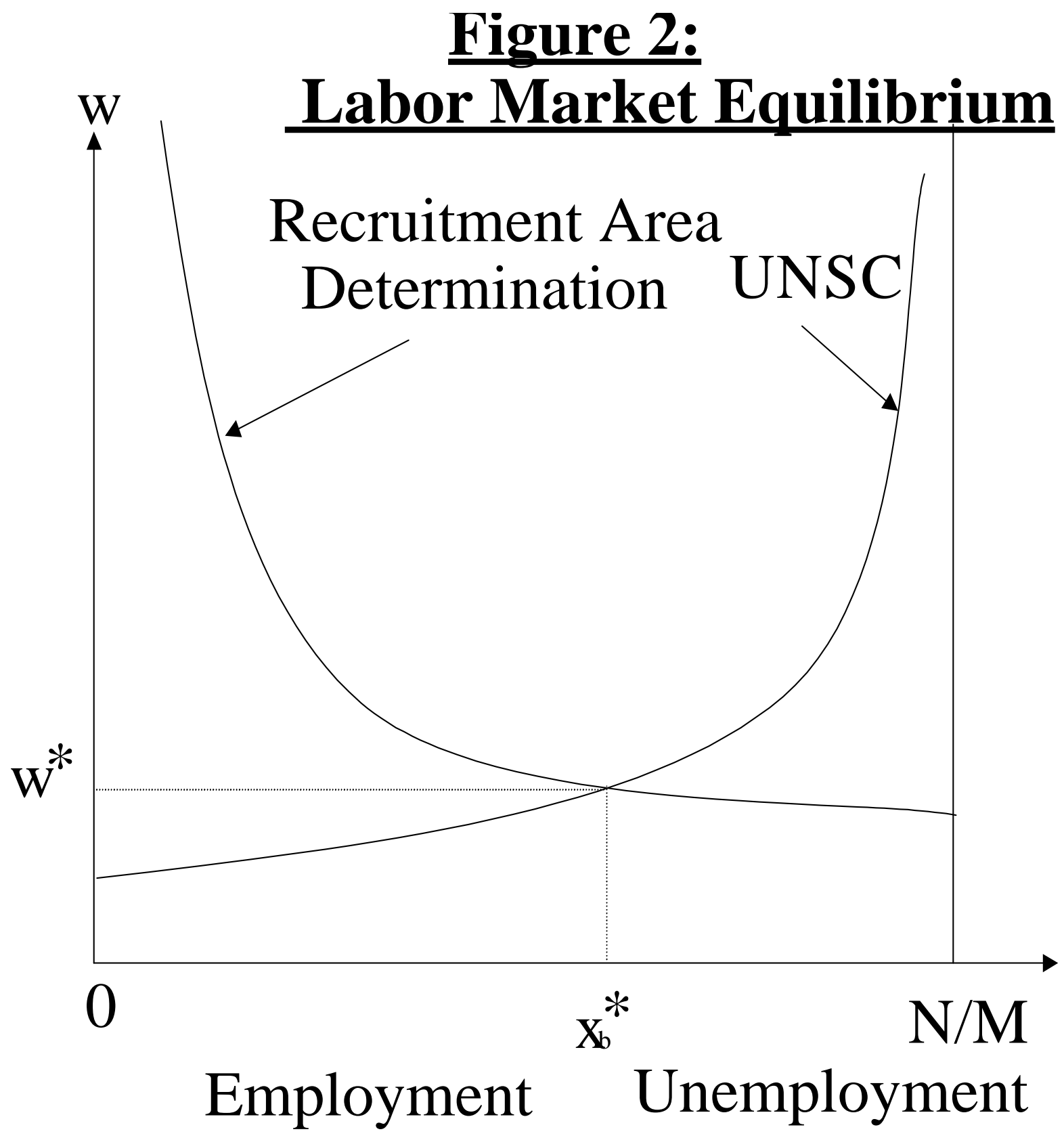




\section{IZA Discussion Papers}

\begin{tabular}{|c|c|c|c|c|}
\hline No. & Author(s) & Title & Area & Date \\
\hline 591 & $\begin{array}{l}\text { H. Görg } \\
\text { E. Strobl }\end{array}$ & $\begin{array}{l}\text { Spillovers From Foreign Firms Through Worker } \\
\text { Mobility: An Empirical Investigation }\end{array}$ & 1 & $10 / 02$ \\
\hline 592 & J. Wagner & $\begin{array}{l}\text { Testing Lazear's Jack-of-All-Trades View of } \\
\text { Entrepreneurship with German Micro Data }\end{array}$ & 5 & $10 / 02$ \\
\hline 593 & $\begin{array}{l}\text { T. K. Bauer } \\
\text { P. J. Dross } \\
\text { J. P. Haisken-DeNew }\end{array}$ & Sheepskin Effects in Japan & 1 & $10 / 02$ \\
\hline 594 & $\begin{array}{l}\text { S. C. Wolter } \\
\text { M. Coradi Vellacott }\end{array}$ & $\begin{array}{l}\text { Sibling Rivalry: A Look at Switzerland with PISA } \\
\text { Data }\end{array}$ & 2 & $10 / 02$ \\
\hline 595 & $\begin{array}{l}\text { W. Arulampalam } \\
\text { A. L. Booth } \\
\text { M. L. Bryan }\end{array}$ & $\begin{array}{l}\text { Work-Related Training and the New National } \\
\text { Minimum Wage in Britain }\end{array}$ & 3 & $10 / 02$ \\
\hline 596 & $\begin{array}{l}\text { H. Görg } \\
\text { E. Strobl }\end{array}$ & $\begin{array}{l}\text { Relative Wages, Openness and Skill-Biased } \\
\text { Technological Change }\end{array}$ & 2 & $10 / 02$ \\
\hline 597 & $\begin{array}{l}\text { S. M. Fuess, Jr. } \\
\text { M. Millea }\end{array}$ & $\begin{array}{l}\text { Disentangling Pay and Productivity in a } \\
\text { Corporatist Economy: The Case of Germany }\end{array}$ & 5 & $10 / 02$ \\
\hline 598 & $\begin{array}{l}\text { D. Del Boca } \\
\text { A. Lusardi }\end{array}$ & $\begin{array}{l}\text { Credit Market Constraints and Labor Market } \\
\text { Decisions }\end{array}$ & 2 & $10 / 02$ \\
\hline 599 & $\begin{array}{l}\text { H. N. Mocan } \\
\text { B. Scafidi } \\
\text { E. Tekin }\end{array}$ & Catholic Schools and Bad Behavior & 5 & $10 / 02$ \\
\hline 600 & $\begin{array}{l}\text { J. S. Lauerová } \\
\text { K. Terrell }\end{array}$ & $\begin{array}{l}\text { Explaining Gender Differences in Unemployment } \\
\text { with Micro Data on Flows in Post-Communist } \\
\text { Economies }\end{array}$ & 4 & $10 / 02$ \\
\hline 601 & $\begin{array}{l}\text { Š. Jurajda } \\
\text { K. Terrell }\end{array}$ & $\begin{array}{l}\text { What Drives the Speed of Job Reallocation } \\
\text { during Episodes of Massive Adjustment? }\end{array}$ & 5 & $10 / 02$ \\
\hline 602 & L. Locher & Migration in the Soviet Successor States & 2 & $10 / 02$ \\
\hline 603 & $\begin{array}{l}\text { T. Andrén } \\
\text { B. Gustafsson }\end{array}$ & $\begin{array}{l}\text { Income Effects from Labor Market Training } \\
\text { Programs in Sweden During the 80's and 90's }\end{array}$ & 2 & $10 / 02$ \\
\hline 604 & $\begin{array}{l}\text { S. P. Jenkins } \\
\text { C. Schluter }\end{array}$ & $\begin{array}{l}\text { The Effect of Family Income during Childhood on } \\
\text { Later-Life Attainment: Evidence from Germany }\end{array}$ & 5 & $10 / 02$ \\
\hline 605 & C. Grund & $\begin{array}{l}\text { The Wage Policy of Firms - Comparative } \\
\text { Evidence for the U.S. and Germany from } \\
\text { Personnel Data }\end{array}$ & 5 & $10 / 02$ \\
\hline 606 & $\begin{array}{l}\text { M. Gerfin } \\
\text { M. Lechner } \\
\text { H. Steiger }\end{array}$ & $\begin{array}{l}\text { Does Subsidised Temporary Employment Get } \\
\text { the Unemployed Back to Work? An Econometric } \\
\text { Analysis of Two Different Schemes }\end{array}$ & 3 & $10 / 02$ \\
\hline 607 & Y. Zenou & How Do Firms Redline Workers? & 5 & $10 / 02$ \\
\hline
\end{tabular}

An updated list of IZA Discussion Papers is available on the center's homepage www.iza.org. 